\title{
Pengaruh Perubahan Fungsi Bangunan pada Bentuk Bangunan Bangsal Banjar Andhap Dalem Mangkubumen Yogyakarta
}

\author{
${ }^{1}$ Nama Tri Yuniastuti dan 2Desy Ayu Krisna Murti \\ 1Dosen, Universitas Widya mataram Yogyakarta,triyuni3@gmail.com \\ 2Dosen, Universitas Widya mataram Yogyakarta, kdesyayu@gmail.com
}

\begin{abstract}
Abstrak
Dalem Mangkubumen awalnya adalah rumah tinggal bagi Putra Mahkota Kraton Yogyakarta calon Sultan Hamengkubuwono VII. Sejak dibangun mulai tahun 1874, Dalem Mangkubumen mengalami perubahan fungsi: awalnya sebagai rumah Pangeran beserta kerabat Kraton, sebagai kampus Universitas Gadjah Mada (1949-1982) dan kampus Universitas Widya Mataram sejak tahun 1982 hingga saat ini. Hal ini mengakibatkan bangunan di Dalem Mangkubumen mengalami perubahan baik tata ruangnya maupun penampilannya termasuk bangunan Bangsal Banjar Andhap.

Penelitian ini dilakukan untuk mengidentifikasi perubahan tata ruang dan penampilan bangunan Bangsal Banjar Andhap akibat perubahan fungsi yang terjadi hingga saat ini. Penelitian ini diharapkan juga dapat mengungkap bagaimana tata ruang dan penampilan bangunan sebelum mengalami perubahan sehingga dapat menjadi acuan melestarikan bangunan yang asli. Agar tujuan penelitian tersebut dapat tercapai, maka cara atau metode yang dinilai tepat digunakan adalah metode grounded yang didasarkan atas penelusuran empirik.

Hasil penelitian menunjukkan bahwa telah terjadi perubahan tata ruang dan penampilan bangunan Bangsal banjar Andhap sejak digunakan sebagai tempat pendidikan Fakultas Hukum Universitas Widya Mataram : yang semula terbuka tanpa dinding karena berfungsi untuk umum, menjadi tertutup berdinding luar dan partisi yang membatasi ruang-ruang Fakultas Hukum UWM. Penambahan material komponen bangunan bersifat semi permanen, sehingga tidak kesulitah apabila suatu saat harus dikembalikan ke bentuk aslinya.
\end{abstract}

Kata kunci: Dalem Mangkubumen, perubahan fungsi, tata ruang, penampilan bangunan, semi permanen.

Kata Kunci: Urbanisme, Ketimuran, Kebaratan

\section{Latar Belakang}

Dikemukan oleh S.Ilmi Albiladiyah, 1985/1986, bahwa ndalem Mangkubumen adalah rumah Pangeran Adipati Anom untuk calon raja Hamengkubuwono VII. Merujuk pada KRT. Mandoyokusumo, 1974, maka Pangeran Mustojo yang telah ditetapkan sebagai calon raja, pada akhirnya diangkat menjadi Sultan Hamengkubuwono ke VII yang bertahta pada tahun 1877-1921

Dalem Mangkubumen tidak lagi menjadi tempat tinggal Pangeran Adipati Anom sebagai Putra Mahkota Kraton Yogyakarta semenjak 5-7 tahun dalem ini didirikan. Hingga kini perubahan fungsi silih berganti. Dari sekian banyak fungsi yang pernah disandang Dalem Mangkubumen, terdapat satu fungsi yang menonjol yaitu fungsi pendidikan, pernah menjadi Kampus UGM, dilanjutkan menjadi kampus Universitas Widya Mataram sejak berdirinya tahun 1982 hingga saat ini.

Dalam proses berjalannya waktu, secara empiris ternyata ditemukan bahwa dalem Mangkubumen tidak saja berfungsi untuk rumah calon raja namun juga untuk rumah pangeran yaitu Pangeran Buminoto (putera pangeran Mangkubumi) dan Pangeran Juminah (putera tertua Sultan Hamengkubuwono VII). Ditemukan juga dari informan bahwa fungsi dalem ini juga sebagai tempat selon yaitu tempat pembuangan bagi para pangeran yang dianggap kurang baik oleh raja. Oleh informan lainnya ditemukan juga fungsi lainnya yaitu sebagai kerandan yaitu sebagai tempat randa-randa (janda) para pangeran (Tri Yuniastuti,dkk., 2014).

Seiring dengan berbagai perubahan fungsi yang terjadi, terutama perubahan besar dari fungsi hunian rumah Pangeran menjadi kampus Universitas Gadjah Mada pada tahun 1949 dilanjutkan Universitas Widya mataram sejak tahun 1982, serta mulai masuknya masyarakat untuk menghuni di kompleks dalem Mangkubumen menjadikan dalem ini, maka banyak terjadi perubahan bentuk dan tata ruang bangunan lama serta penambahan bangunanbangunan baru yang berfungsi sebagai kampus dan hunian masyarakat.

Khususnya pada bangunan Bangsal Banjar Andhap, juga terdapat perubahan bentuk dan tata ruang 
bangunan yang diakibatkan oleh perubahan fungsi atau penggunaannya.

Atas dasar itulah maka dirumuskan permasalahnya yaitu:

a. Fungsi apa saja yang mengakibatkan perubahan (pengurangan, penambahan, dan perbaikan) tata ruang Bangsal Banjar Andap?

b. Bagaimana perubahan bentuk arsitektur yang terjadi pada bangunan Bangsal Banjar Andap akibat tuntutan fungsi bangunan yang berkembang hingga saat ini ?

Tujuan dari penelitian ini adalah mengungkap perubahan tata ruang dan bentuk arsitektur bangunan Bangsal Banjar Andhap Dalem Mangkubumen Yogyakart setelahberubah fungsi menjadi kampus Kampus UGM maupun UWM hingga saat ini. Diharapkan dengan terungkapnya perubahan tata ruang dan bentuk arsitektur bangunan Bangsal Banjar Andhap Dalem Mangkubumen tersebut dapat menjadi pengetahuan penting dalam rangka pengembangan ilmu arsitektur khusususnya dalam upaya pelestarian Arsitektur Tradisional Jawa sebagai karya budaya bangsa dan pengendalian perkembangannya.

\section{Studi Pustaka}

Dalam proses berjalannya waktu, secara empiris ternyata ditemukan bahwa dalem Mangkubumen tidak saja berfungsi untuk rumah calon raja namun juga untuk rumah pangeran yaitu Pangeran Buminoto (putera pangeran Mangkubumi) dan Pangeran Juminah (putera Sultan Hamengkubuwono VII). Ditemukan juga dari informan bahwa fungsi dalem ini juga sebagai tempat selon yaitu tempat pembuangan bagi para pangeran yang dianggap kurang baik oleh raja. Oleh informan lainnya ditemukan juga fungsi lainnya yaitu sebagai kerandan yaitu sebagai tempat randa-randa (janda) para pangeran (Tri Yuniastuti,dkk., 2014).

Berdasarkan studi lapangan melalui pengamatan objek secara langsung dan wawancara kepada informan yang sejak lama tinggal di dalam Komplek Dalem Mangkubumen, dapat terungkap sejarah arsitektur maupun fungsi bangunan Dalem Mangkubumen sebelum tahun 1949, salah satunya adalah bangsal Banjar Andhap.

Bangsal Banjar Andap adalah bagian dari dalem Mangkubumen yang berada di bagian terdepan. Pada masanya, disekeliling bangsal berupa pelataran luas tanpa bangunan; di depannya didapati jalan utama dalem arah Selatan, disebelah kanan dan kiri didapati juga akses berupa jalan ke arah Timur dan Barat. Arah hadap utama dari bangunan ini adalah ke arah Selatan.

Berdasarkan data hasil wawancara dengan penghuni setempat , fungsi utama bangunan bangsal Banjar Andap ini adalah sebagai tempat jaga yang pertama. Bangunan tersebut dilengkapi dengan jam yang berupa kenthongan besar yang ditabuh/dipukul. Fungsi lainnya adalah sebagai ruang tunggu bagi para tamu agung yang akan menghadap Pangeran (Tri Yuniastuti, dkk, 2014).

Bangunan asli yang ada di dalam kompleks Dalem Mangkubumen yang masih ada saat ini antara lain :Bangsal Proboyekso, Bangsal Alit, Bangsal Pringgitan, Gedhong Inggil, Pendapa Agung, Regol Cemeng dan Bangsal Banjar Andhap.Tembok-tembok pembatas halaman dan regol-regol penghubung juga masih berdiri dan membagi wilayah Dalem Mangkubumen menjadi beberapa halaman. Tata letak bangunan dan pembagian wilayah tersebut dapat dilihat pada gambar berikut :

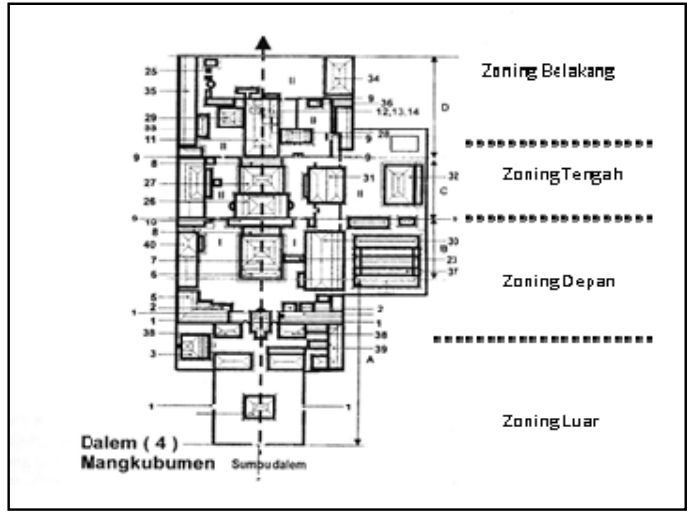

Gambar 1. Denah Dalem Mangkubumen. Sumber :Tri Yuniastuti, dkk., 2014

Menurut Tri Yuniastuti \& Satrio HBW, 2010, Dalem Mangkubumen memiliki beberapa karakteristik bentuk bangunan. Menurut Arsitektur Tradisional Jawa DIY maka ada empat typology bentuk bangunan Dalem Mangkubumen yaitu bentuk Joglo, limasan, kampung dan tajug.Tipologi bentuk joglo dipakai pada bangunan-bangunan utama khususnya untuk bangunan pendhapa yaitu bangunan yang sifatnya terbuka (umum) termasuk pendhapa banjar andhap. Selanjutnya dikatakan bahwa bila dilihat dari sifat bentuk bangunannya, maka terbagi manjadi dua yaitu terbuka dan tertutup. Bangunan terbuka berarti tidak terdapat sekat penutup baik berupa dinding permanent maupun semi permanent, sedangkan yang tertutup terdapat sekat-sekat penutup yang mengelilingi bangunan.

Ditinjau dari bentuk bangunannya, bangsal Banjar Andap menggunakan gaya bangunan tipe joglo sinom dengan sifat bangunan terbuka (Tri Yuniasturi dan Satrio HB Wibowo, 2010).

\section{Metode}

Objek Penelitian adalah bangunan Bangsal Banjar Andhap yang berada di kompleks Dalem Mangkubumen, Kecamatan Kraton, Kotamadya Yogyakarta, DIY, berjarak kurang lebih 300 meter ke arah Barat dari Kraton Yogyakarta.

Pengumpulan data dilakukan dengan wawancara, observasi dan penelusuran dokumen. 
Menurut Norman K. Denzin dan Y Yvonna S. Lincoln (h.495, 2009) mengungkapkan bahwa wawancara adalah bentuk perbincangan, seni bertanya dan mendengar. Menurutnya terdapat tiga bentuk wawancara yaitu terstruktur, tak terstruktur dan terbuka. Dalam proses wawancara selain mencatat berbagai informasi juga dengan cara merekam suara dengan alat rekam audio MP3. Perekaman suara selanjutnya ditulis ulang menjadi logbook. Wawancara dilakukan kepada pejabat Struktural dan orang-orang yang memanfaatkan bangunan tersebut untuk mendapatkan data tentang perubahan fungsi bangunan dan perubahan tata ruang maupun bentuknya.

Observasi menurut Mortis (1973) dalam Norman K. Denzin dan Y Yvonna S. Lincoln (2009) merupakan aktifitas mencatat suatu gejala dengan bantuan instrumen-instrumen dan merekamnya demi tujuan ilmiah atau tujuan lain. Metode ini tidak saja hanya mengumpulkan data visual saja melainkan juga seluruh indera; dengan demikian observasi terdiri atas kumpulan kesan tentang dunia sekitar berdasarkan semua kemampuan daya serap panca indera manusia. Observasi dilakukan langsung oleh peneliti dengan cara memfoto dengan kamera digital, mencatat, mengukur, dan sketsa untuk mendokumentasikan tata ruang dan bentuk arsitektur Bangsal Banjar Andhap Dalem Mangkubumen Yogyakarta.

Data yang diperlukan dalam menelusuri perubahan tata ruang dan bentuk bangunan Bangsal Banjar Andhap Dalem Mangkubumen juga didapatkan dari gambar-gambar proyek, laporan penelitian, jurnal, berita di koran, majalah, serta dari internet.

Sesuai dengan tata kerja penelitian grounded maka analisis data berproses/berlangsung selama riset berlangsung dan dimulai dari pencarian data awal hingga akhir pengamatan. Proses analisis menggunakan prinsip dari Glasser (1969 dimulai dari Coding (pelabelan), kategorisasi, dan penarikan kesimpulan.

\section{Analisis dan Pembahasan}

\section{a. Dalem Mangkubumen}

Menurut inskripsi yang terdapat di beberapa bangunan dalam komplek Dalem Mangkubumen dapat diketahui bahwa peendirian bangunan dilaksanakan pada tahun 1874 hingga 1905. Tahun 1874 adalah pendirian Bangsal Sriwedari dan tahun 1905 adalah pendirian Pendapa Agung. Bangsal Banjar Andhap sebagai kesatuan dalam komplek Dalem Mangkubumen diperkirakan dibangun pada masa antara 1874-1905.

Dari hasil penelusuran data yang didapatkan, secara garis besar perubahan fungsi Dalem Mangkubumen pada umumnya dan Bangsal Banjar Andhap khususnya dapat dikategorikan dalam kurun waktu :

1. Sejak berdiri hingga tahun 1877 sebagai tempat tingal Pangeran Adipati Anom atau Pangeran Pati yang kemudian menjadi Sri Sultan Hamengku Buwono VII (1877-1821)

2. Sejak 1877 sebagai tempat tinggal Pangeran Mangkubumihingga tahun 1918, Pangeran Juminah hingga tahun 1928, keluarga Kraton dan keluarga abdi dalem secara turun temurun hingga sekarang.

3. Sejak 1949 sebagai Kampus Universitas Gajah Mada dan Rumah Sakit Mangkubumen hingga tahun 1975.

4. Sejak 1982 hingga saai ini sebagai kampus Universitas Widya Mataram berdampingan dengan SMA Mataram, TK Tejokusuman sejak 1991 dan SD Tumbuh menempati bekas SMA Mataram.

Bangsal banjar Andhap yang terletak di bagian depan Dalem Mangkubumen juga mengalami berbagai fungsi. Dari penge- lompokan periodisasi tersebut, perubahan fungsi Banjar Andap dapat dirumuskan sebagai berikut :

Tabel 1. Periodisasi Fungsi Bangunan Bangsal Banjar Adhap

\begin{tabular}{|c|c|l|}
\hline NO. & $\begin{array}{l}\text { PERIODI- } \\
\text { SASI }\end{array}$ & \multicolumn{1}{c|}{ FUNGSI } \\
\hline 1. & $1874-1877$ & $\begin{array}{l}\text { Tempat caos atau } \\
\text { berkumpulnya para pegawai } \\
\text { Kadipaten (pegawai } \\
\text { Pangeran Adipati Anom) } \\
\text { dan sebagai tempat } \\
\text { persiapan para pegawai } \\
\text { untuk mengiring bila } \\
\text { Pangeran Putra Mahkota } \\
\text { bepergian }\end{array}$ \\
\hline 2. & $1877-1949$ & $\begin{array}{l}\text { Sebagai tempat jaga yang } \\
\text { pertama, dilengkapi dengan } \\
\text { jam yang berupa kenthongan } \\
\text { besar yang ditabuh/dipukul. } \\
\text { Sebagai ruang tunggu bagi } \\
\text { para tamu agung yang akan } \\
\text { menghadap Pangeran }\end{array}$ \\
\hline 3. & $1949-1975$ & $\begin{array}{l}\text { Tahun 1967 digunakan } \\
\text { sebagai kompleks } \\
\text { Kedokteran Gigi Universitas } \\
\text { Gadjah Mada }\end{array}$ \\
\hline 4. & 1982 & $\begin{array}{l}\text { Sejak tahun 2000 digunakan } \\
\text { untuk Laboraturium } \\
\text { Fakultas Hukum Universita } \\
\text { Widya Mataram }\end{array}$ \\
\hline sekarang
\end{tabular}

Sumber : Analisis Data

Sebelum digunakan sebagai Laboratorium Fakultas Hukum UWM, bangunan Bangsal Banjar Andhap dulunya berfungsi untuk umum, siapapun bisa masuk ke dalam bangunan untuk beristirahat. 
Tabel 2. Letak dan Tipologi Bangunan Tradisional di Dalem Mangkubumen

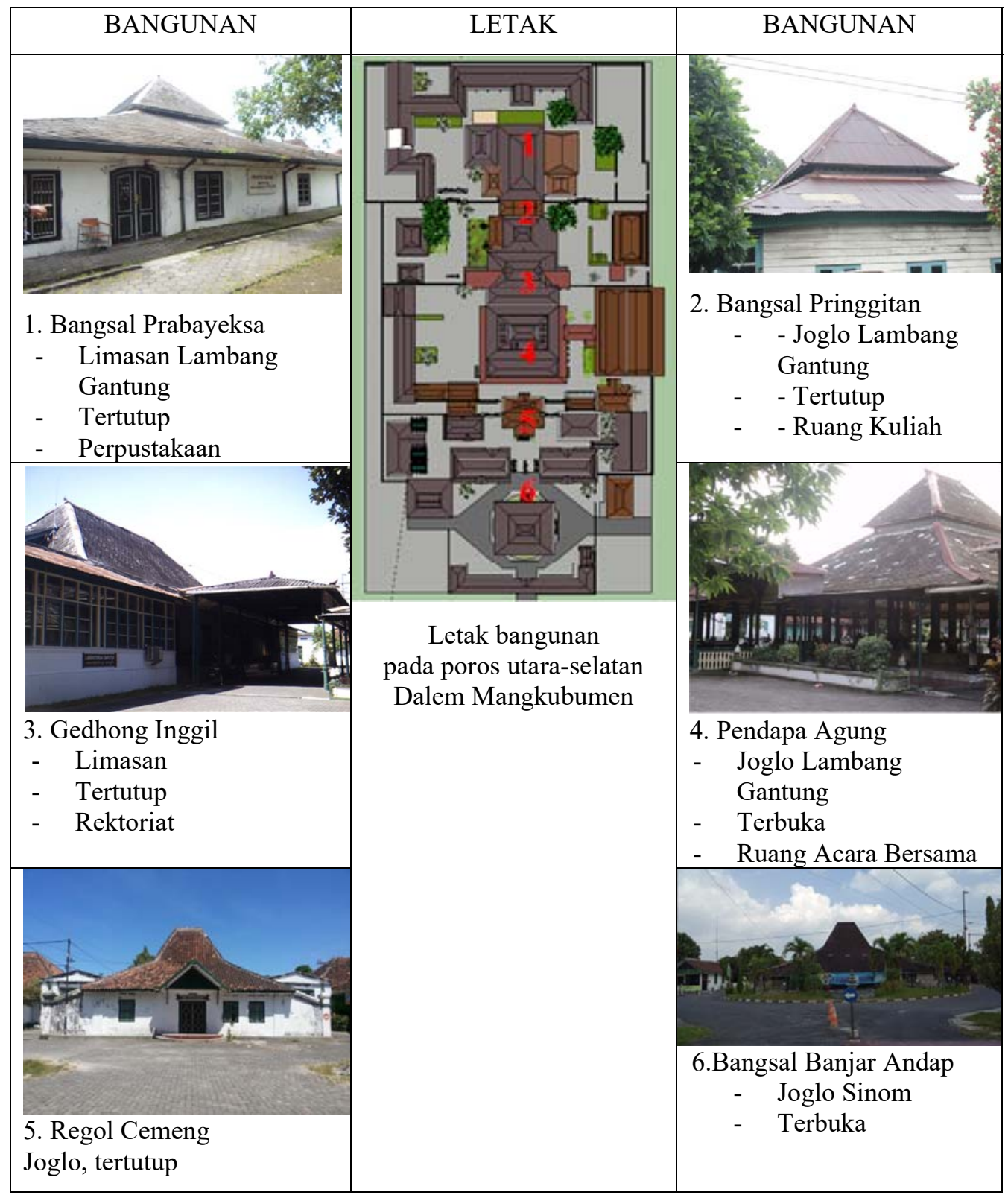

Sumber : Analisis Data

b. Bangsal Banjar Andhap

Bangunan Bangsal Banjar Andhap terletak pada bagian depan dari komplek dalem Mangkubumen karena awalnya berfungsi sebagai penerima tamu

Bentuk arsitekturnya bangsal Banjar Andhap termasuk kategori tipologi joglo sinom; awalnya bersifat berbuk tidak terdapat sekat atau partisi/dinding sebagai penutup ruangan; sehingga disebut pendapa atau bangunan yang terbuka. Karakteristik joglo sinom ini adalah model atap berbentuk joglo yang setingkat lebih besar dari joglo lawakan. Atapnya tersusun menjadi tiga tingkatan yaitu atap penitih dibagian bawah, penanggap di bagian tengah dan brunjung di bagian atas sebagai puncaknya. Bentuk atap joglo ini didukung oleh konstruksi balok tumpangsari; $36 \mathrm{saka/tiang/kolom} \mathrm{dari} \mathrm{kayu} \mathrm{jati}$ dengan ukuruan tertentu yang terdiri dari 4 saka guru (saka utama), 12 saka penanggap dan 20 saka penitih; dan masing-masing saka itu berdiri diatas sebuah batu berbentuk trapezium berukir yang disebut umpak. 


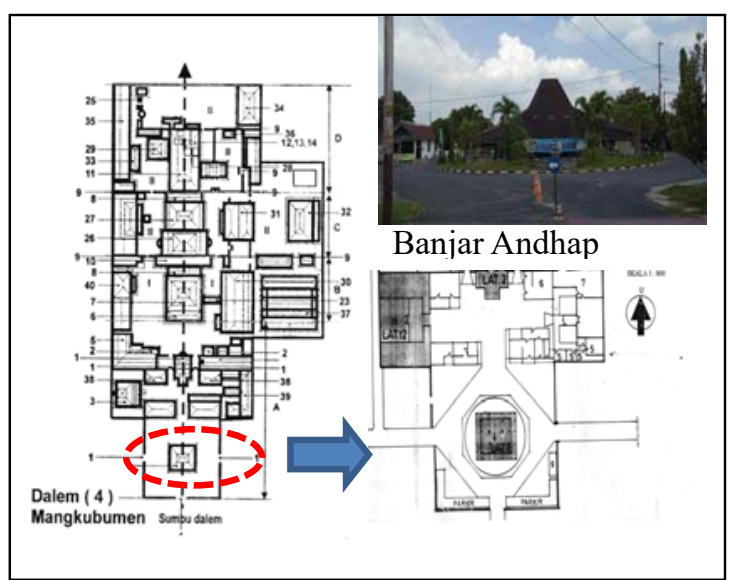

Gambar 2. Letak Bangunan Bangsal Banjar Andhap dalam Komplek Dalem Mangkubumen

Sumber : Analisis Data

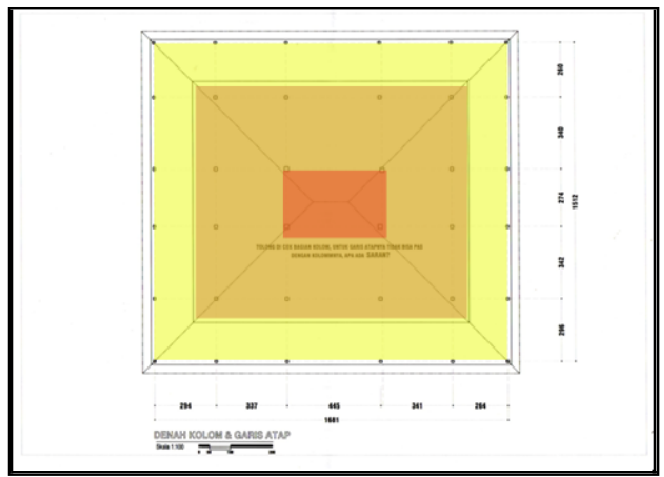

Gambar 3. Denah Awal Bangsal Banjar Andhap

Sumber : Redrawing, 2019, diolah

Bentuk dasar ruang Bangsal Banjar Andhap adalah kotak yaitu persegi panjang yang mendekati kearah persegi seperti halnya bangunan-bangunan joglo Jawa lainnya. Sedangkan keruangan bangsal ini terbagi atas dua ruangan yaitu ruang penitih yang berada di bagian bawah dan ruang penanggap di bagian atas yang dikelilingi oleh ruang penitih.Aslinya batas antar ruangan yang ada berupa berupa perbedaan ketinggian lantai (split level). Bahan lantai sudah mengalami pergantian, dari semula menggunakan tegel abu-abu ukuran 20x20 ditumpangi Keramik putih ukuran $30 \mathrm{~cm} 30 \mathrm{~cm}$ di atasnya.

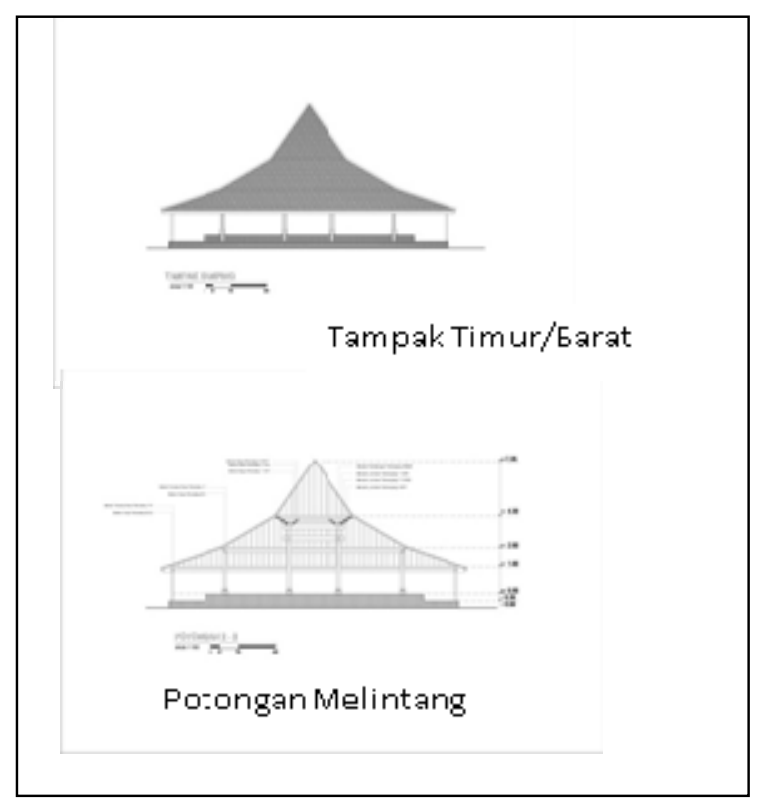

Gambar 4. Tampak dan Potongan Melintang Bangsal Banjar Andap Sumber : Redrawing, 2019

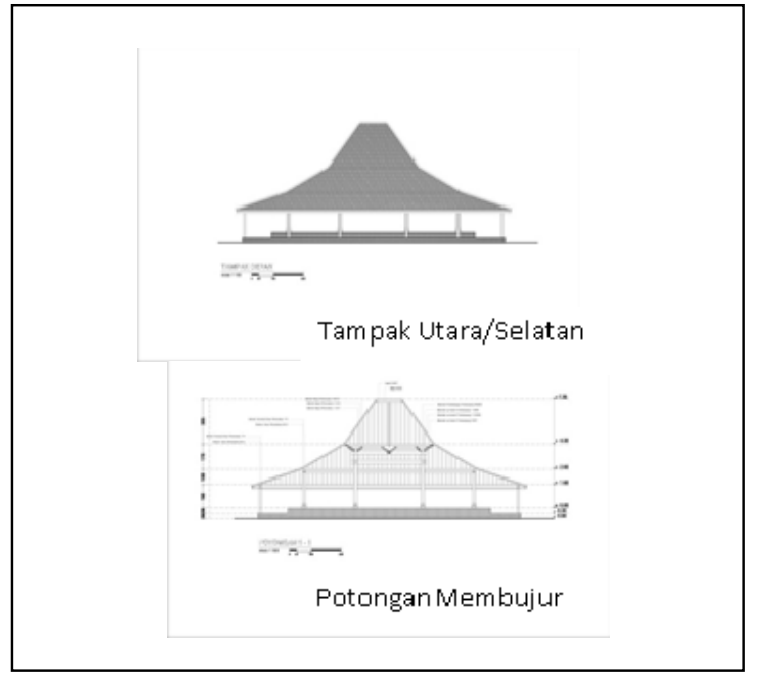

Gambar 5. Tampak dan Potongan Membujur Bangsal Banjar Andap Sumber : Redrawing, 2019 


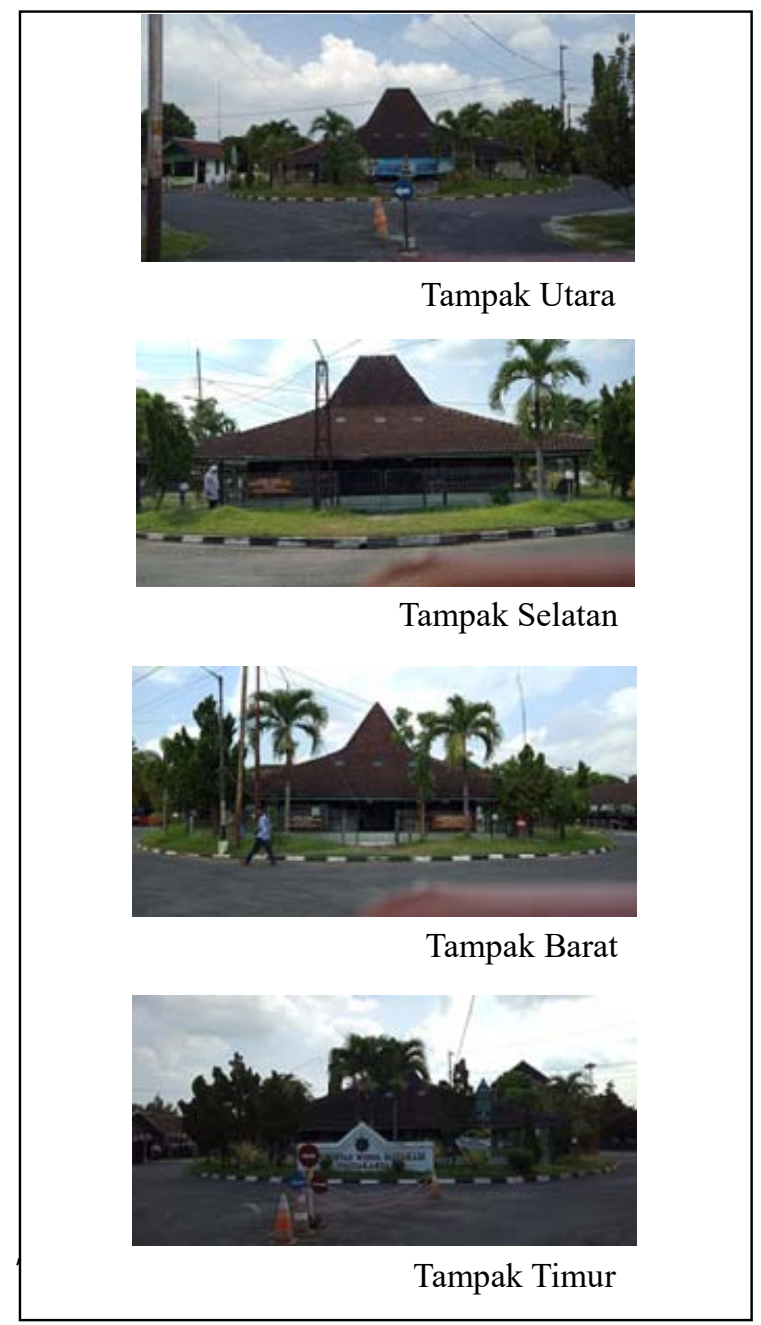

Gambar 6. Tampak Bangunan Bangsal Banjar Andhap

Sumber : Pengamatan, 2019

\section{c. Perubahan Fungsi dan Bentuk Bangunan}

1) Perubahan Fungsi

Perubahan fungsi bangunan Bangsal Banjar Andhap berdasarkan periodisasi pemanfaatan bangunan : pada masa sebelum digunakan untuk UGM, Pada saat dipakai sebagai kampus UGM dan pada saat digunakan sebagai kampus UWM hingga saat ini.

Sebelum digunakan UGM sebagai kampus, fungsi utama bangunan bangsal Banjar Andap ini adalah sebagai tempat jaga yang pertama. Bangunan tersebut dilengkapi dengan jam yang berupa kenthongan besar yang ditabuh/dipukul. Fungsi lainnya adalah sebagai ruang tunggu bagi para tamu agung yang akan menghadap Pangeran.

Pada masa pemakaian untuk Kampus UGM, Bangsal Banjar Andhap awalnya berfungsi sebagai pos keamanan pertama dan ruang tunggu, kemudian pada tahun 1967 berfungsi untuk kegiatan kompleks Kedokteran Gigi Universitas
Gadjah Mada (Sutaryo, 2016).

Ketika Dalem Mangkubumen sebagai Kampus UWM, pada awalnya Bangsal Banjar Andhap tidak difungsikan untuk fasilitas pendidikan, namun dibiarkan terbuka untuk istirahat bagi siapapun yang lewat, bahkan sering digunakan oleh para gelandhangan sebagai tempat istirahat. Namun kemudian, karena tuntutan kebutuhan ruang, bangsal Banjar Andhap dimanfaatkan Fakultas Hukum UWM untuk kegiatan Laboraturium dan kegiatan Dosen (Wawancara dengan Pejabat Dekan Fakultas Hukum, 2019).

Pemanfaatan Bangunan Bangsal Banjar Andhap untuk keperluan proses pendidikan Fakultas Hukum UWM antara lain :

- Laboraturium Hukum

- Pusat Studi HAM dan Hukum Humaniter

- Pusat Studi Hukum dan Konstitusi

- Pendidikan Khusus Profesi Advokat (PKPA)

Kegiatan yang ada di dalam bangunan Bangsal Banjar Andhap saat ini meliputi :

- Kegiatan Pendidikan : Perkuliahan, Ujian S1, Pendidikan Profesi

- Kegiatan Perkantoran : Pengelola Kepala Laboraturium dan Pusat Studi

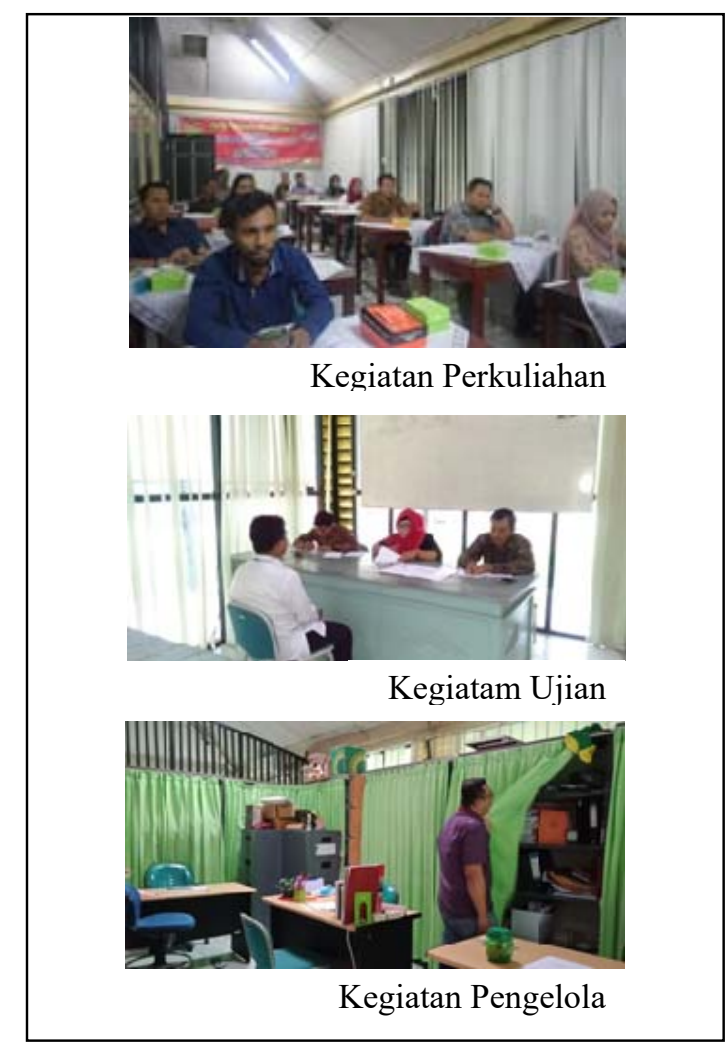

Gambar 1. Kegiatan di dalam Bangunan Bangsal Banjar Andap Sumber : Dokumentasi, 2019 
2) Perubahan Bentuk Bangunan Bangsal Banjar Andhap

Bagian atap bangunan tidak berubah, sehingga bentuk bangunan ini secara keseluruhan bila dilihat dari luar tidak berubah, akan tetapi fasad bangunannya yang berubah.

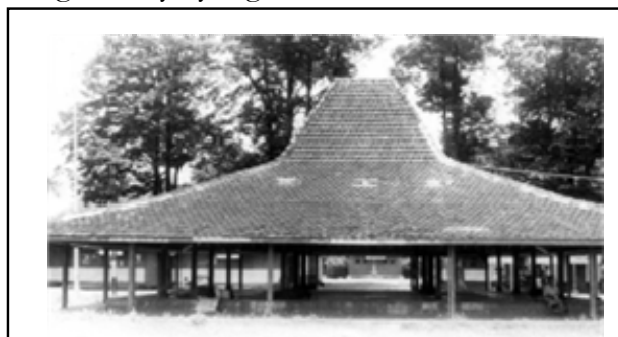

Sebelumnya untuk kegiatan umum : berteduh, beristirahat. Bentuk bangunan terbuka, tanpa pagar dan tanpa dinding.

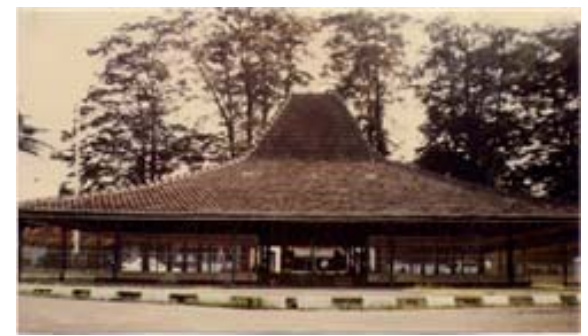

Setelah difungsikan sebagai Kampus UWM :

- Untuk kegiatan internal

- Bangunan dibatasi pagar GRC

- Terdapat pembatas/marka jalan melingkari bangunan

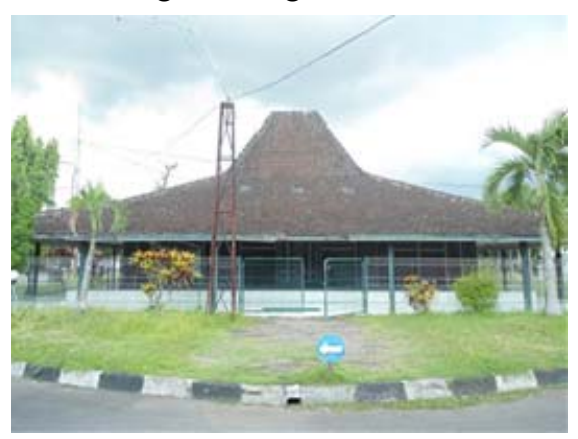

Setelah bangunan difungsikan untuk Laboraturium Fakultas Hukum hingga saat ini, pada bagian Penanggap ditutup partisi dari kayu dan kaca. Ada menara besi, dahulu untuk pemancar radio mahasiswa.

Gambar 8. Perubahan Bentuk Bangunan Bangsal Banjar Andhap Sisi Selatan Sumber: Analisis Data
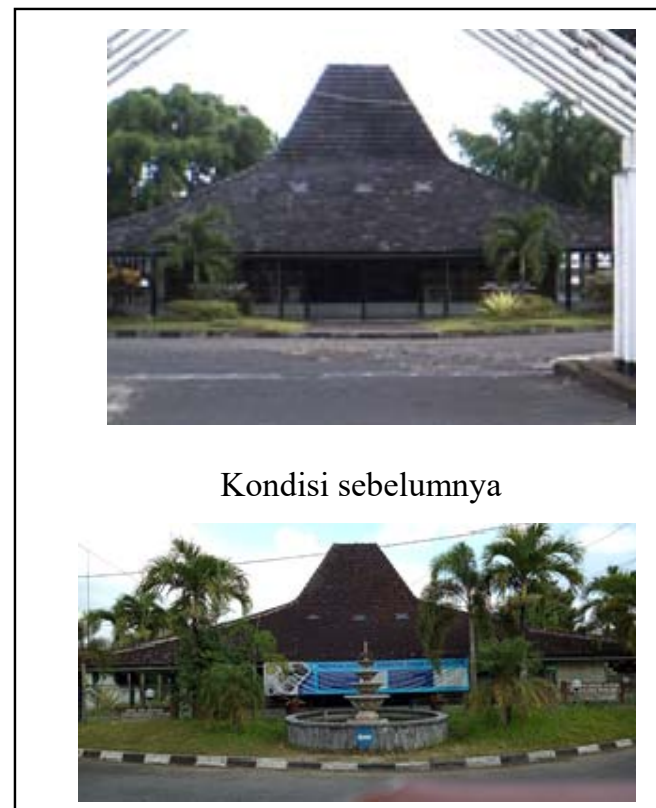

Ada penambahan air mancur untuk mempercantik penampilan

Gambar 2. Perubahan Bentuk Bangunan Bangsal Banjar Andhap Sisi Utara Sumber : Analisis Data

3) Perubahan Tata Ruang Bangunan Bangsal Banjar Andhap

Akibat perubahan fungsi Bangsal Banjar Andhap dari masa ke masa, perubahan juga terjadi pada bentuk bangunan bangsal ini. Perubahan yang sangat signifikan adalah sejak difungsikan untuk kegiatan pendidikan Fakultas Hukum UWM, sekitar tahun 2000 hingga kini,Bangsal Banjar Andhap ini berubah menjadi bangsal yang tertutup.

Perubahan tata ruang bangunan yang terjadi antara lain :

- Penambahan partisi dinding dan kacamengikuti keliling tiang penanggap sehingga membentuk ruang dalam dan menjadikan bangsal ini bersifat tertutup.

- Lantai bangunan yang semula permukaannya tegel berundag ditutup dengan keramik de, sehingga ketinggian lantainya berubah dari semula. Hal ini dapat dilihat pada bagian umpak yang tertutup lantai pada bagian bawahnya.

- Di bagian lantai bawah/luar (penitih)masih terbuka dansudah dikelilingi pagar BRC sejak tahun 1990-an.

- Bagian dalam bangunan diberi partisi dinding untuk membentuk ruang-ruang dengan mengikuti pola tiang yang ada. 


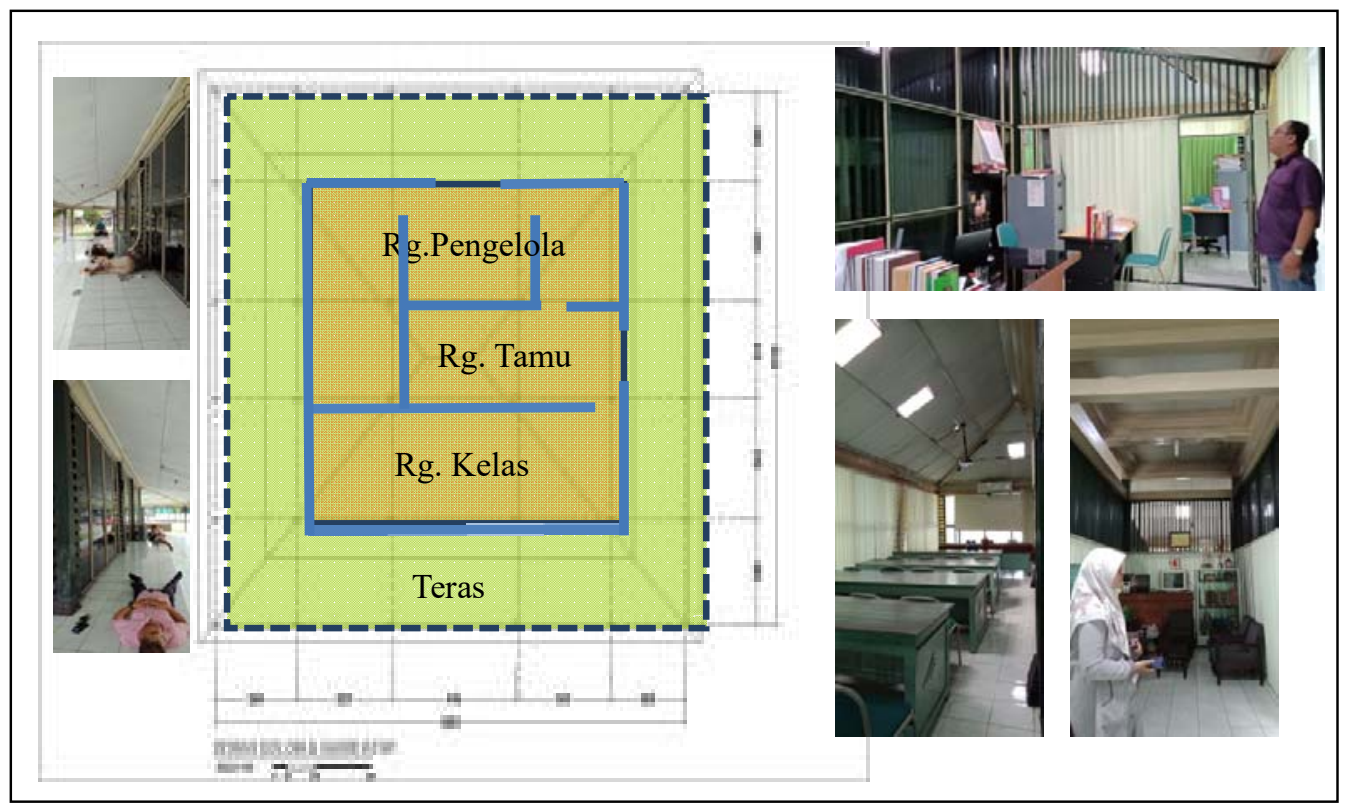

Gambar 10. Denah Bangunan Bangsal Banjar Andhap dan Penggunaan Ruang Sumber : Analisis Data Lapangan

Terbentuknya ruang-ruang di dalam Bangunan Bangsal Banjar Andhap untuk mewadahi kegiatan yang berlangsung, banyak menggunakan bahan bangunan yang bersifat tidak permanen sehingga mudah dibongkar apabila suatu saat bangunan tersebut harus dikembalikan pada bentuk aslinya. Macam bahan bangunan dan penggunaannya untuk mewujudkan ruang dalam bangunan Bangsal Banjar Andap dapat dilihat pada tabel berikut.

Tabel 3. Penambahan Komponen dan Elemen Bangunan Bangsal Banjar Andhap

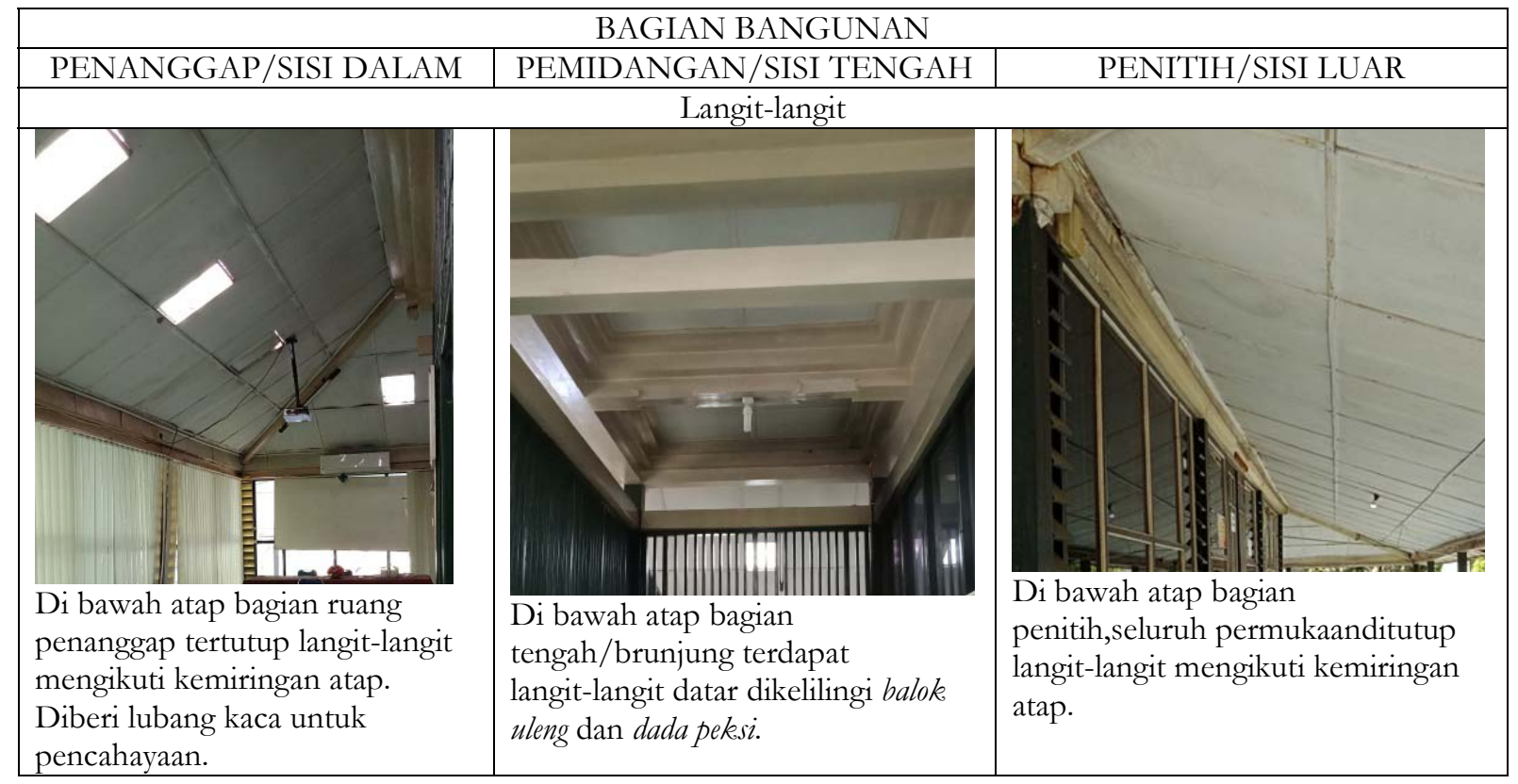




\begin{tabular}{|l|l|l|l|}
\hline \multicolumn{5}{|c|}{ BAGIAN BANGUNAN } \\
\hline PENANGGAP/SISI DALAM & PEMIDANGAN/SISI TENGAH & PENITIH/SISI LUAR \\
\hline & & Dinding & \\
\hline
\end{tabular}

Sumber : Analisis Data

\section{Kesimpulan dan Masukan}

a. Kesimpulan

Dari hasil penelusuran terhadap dokumen yang ada, hasil penelitian dan wawancara kepada para pengguna bangunan dapat disimpulkan bahwa, sejak berdirinya hingga saat ini, Dalem Mangkubumen mengalami perubahan fungsi yang mengakibatkan perubahan pada bentuk bangunannya. Perubahan fungsi dapat dikelompokan berdasarkan masa pemakaian bangunan, mulai sejak berdiri sebagai Dalem Pangeran Pati, sebagai kediaman Pangeran Mangkubumi dan kerabat Kraton, sebagai Kampus UGM dan sebagai kampus Universitas Widya Mataram. Perubahan fungsi tersebut berdampak langsung pada perubahan bentuk bangunannya baik dalam penambahan bangunan/ruang maupun penggatian komponen bangunan.
Khususnya pada angunan Bangsal Banjar Andap, perubahan yang terjadi tidak merubah bentuk keseluruhan bangunan, namun merubah tata ruang di dalamnya dengan menambah komponen langit-langit, dinding dan lantainya. Sehingga bangunan yang tadinya terbuka menjadi tertutup. Perubahan tersebut banyak terjadi pada masa penggunaannya sebagai tempat pendidikan bagi Fakultas Hukum Universitas Widya Mataram karena tuntutan kebutuhan akan Ruang Laboraturium/ Pusat Studi dan Ruang Kerja Dosen sebagai Pengelola Laboraturium sekaligus Ruang kuliah/ Pelatihan.

Kebijakan Pejabat yang berwenang untuk menambahelemen dan komponen bangunan untuk membentuk ruang dalam bangunan Bangsal Banjar Andhap sudah mempertimbangkan apabila 
sewaktu-waktu harus dikembalikan ke bentuk semula tidak mengalami kesulitan karena dibuat secara semi permanen dengan bahan bangunan yang mudah dibongkar.

b. Masukan

Berhubung bangunan Bangsal banjar Andhap merupakan bagian dari Dalem Mangkubumen yang merupakan Bangunan Cagar Budaya, maka bila akan melakukan perubahan baik itu penambahan maupun penggantian komponen bangunan sebaiknya melakukan ijin secara tertulis kepada pihak yang terkait dan berwenang agar tidak menjadi maslah di kemudian hari.

Karena bangunan Bangsal Banjar Andhap sudah berumur lebih dari 100 tahun, maka perlu pemeliharaan yang dan perbaikan komponen bangunan yang rusak agar tidak membahayakan bagi para pemakainya. Hal ini tidak hanya menjadi tanggungjawab bagi pengguna bangunan untuk senantiasa merawat dan memeriksa kerusakan yang terjadi, namun bagi para pemerhati bangunan cagar budaya untuk selalu meneliti untuk mengidentifikasi kerusakan yang perlu diusulkan untuk diperbaiki oleh pihak yang berwenang dalam hal ini Dinas yang terkait, yaitu Dinas Kebudayaan.

\section{Referensi}

Anselm Strauss \& Juliet Corbin, 2009, Dasar-dasar Penelitian Kualitatif, Tata Langkah dan Teknik-teknik Teorisasi Data, Pustaka Pelajar, Yogyakarta.

Barney G. Glaser and Anselm L. Strauss, 1967, The Discovery of Grounded Theory Strategies for Qualitative Research, Aldine Publishing Company, Chicago.

HJ. Wibowo, Drs., dkk., Rumah Tradisional Daerah Istimewa Yogyakarta, Departemen Pendidikan dan Kebudayaan Proyek Inventarisasi dan Dokumentasi Kebudayaan Daerah, 1986.

Joseph Prijotomo, 2005, Pengkonstruksian Sektor Guru dari Griya Jawa: Tafsir atas Kawruah Kalang, Jurnal Ilmiah Dimensi Volume 33 Nomor 2, Lembaga Penelitian dan Pengabdian Keada masyarakat Universitas Kristen Petra, Surabaya.

KGPH Hadiwinoto, 2005, Pelestarian dan Pengembangan Kepurbakalaan Dalem Mangkubumen, Makalah pada Focus Group Discussion, Universitas Widya Mataram
Yogyakarta.

KRT. Mandoyokusumo, 1974, Serat Raja Putra Ngayogyakarta Hadiningrat, Musium Kraton Ngayogyakarta Hadiningrat, Yogyakarta.

Koentjaraningrat. (1994). Kebudayaan Mentalitas dan Pembangunan. Jakarta : PT Gramedia Pustaka Utama.

Norman K. Denzin \& Yvonna S. Lincoln, 2009, Handbook of Qualitative Research, Pustaka Pelajar, Yogyakarta.

Rapoport, Amos. (1969). House Form and Culture. Englewood Cliffs,N.J : Prentice-Hall, Inc.

Santosa, Revianto Budi. (2000). Omah : Membaca Makna Rumah Jawa. Yogyakarta : Yayasan Bentang Budaya.

S. Ilmi Albiladiyah, Dalem Mangkubumen Kodya Yogyakarta dan Kompleks Makam Girigondo Temon Kulonprogo, Balai Kajian Sejarah dan Nilai Tradisional Yogyakarta, 1985/1986.

Siti Widayatsari, 2002, Tata Ruang Rumah Bangsawan Yogyakarta, dalam Jurnal ILmiah Dimensi Volume 30 Nomor 2, Lembaga Penelitian dan Pengabdian Keada masyarakat Universitas Kristen Petra, Surabaya.

Soemardjan, Selo. (1991). Perubahan Sosial di Yogyakarta. Yogyakarta : Gadjah Mada University Press.

Sukirman, Drs, Dkk, 1999, Identifikasi Ragam Hias pada Bangunan Pendapa Agung Dalem Mangkubumen Yogyakarta, LPPM-UWMY.

Sutaryo, 2016, Sejarah Fakultas Kedokteran UGM-Rumah Sakit UGM/RSUP Dr. Sardjito, Puspagama, Yogyakarta.

Tri Yuniastuti dan Satrio HB Wibowo, 2010, Perubahan Bentuk bangunan Dalem Mangkubumen Yogyakarta, LPJJ, Yogyakarta.

Tri Yuniastuti, dkk., 2014, Mengungkap Sejarah Arsitektural DalemMangkubumen Yogyakarta Periode Tahun 1874-1949, LPPM-UWMY. 